\title{
Spacing effects in cued-memory tasks for unfamiliar faces and nonwords
}

\author{
NICOLA MAMMARELLA, RICCARDO RUSSO, and S. E. AVONS \\ University of Essex, Colchester, England
}

\begin{abstract}
Memory for repeated items improves as the interval between repetitions in a list increases (the spacing effect). This study investigated the spacing effect in recognition memory and in a frequency judgment task for unfamiliar target faces that were repeated in the same or in a different pose during incidental learning. Changing the pose between prime and probe trials reduced perceptual repetition priming in a structural discrimination task and also reduced the spacing effect in a subsequent unexpected recognition memory task. Three further experiments confirmed that the spacing effectin recognition memory (Experiments 2 and 4 ) or frequency judgment (Experiment 3) was reduced when the pose was changed between repeated presentations at study. Similarly, with nonwords as targets (Experiment 5), changing the font between repeated occurrences of targets at study removed the spacing effect in a subsequent unexpected recognition memory test. These results are interpreted to support the view that short-term perceptual repetition priming underlies the spacing effect in explicit cuedmemory tasks for unfamiliar nonsense material.
\end{abstract}

Items repeated within a list after some other intervening items (spaced items) are usually better remembered than when no intervening items separate the repetitions (massed items). This phenomenon, called the spacing effect, is ubiquitously observed in explicit memory tasks such as free recall and recognition memory (for reviews see Crowder, 1976; Greene, 1989; Hintzman, 1974). Although apparently simple, the spacing effect has defied a unitary explanation, and at present different mechanisms are invoked to account for the spacing effect in free recall and in explicit cued-memory tasks. Greene suggested that, in free recall, which is highly sensitive to contextual associations of list items, spaced items were advantaged by additional encoding of contextual information relative to massed items. Thus the second occurrence of an item in a list reminds the observer of the previous occurrence of the same item and of the contextual features surrounding that item. When the items are spaced, this reminding process ensures that different contextual features are associated with the same list item, whereas for massed items the difference in context will be relatively small. Thus there are more retrieval cues available for spaced items than for massed items, leading to improved recall. Consistent with this suggestion, comparable spacing effects were found in the free recall of words after in-

This research was supported by an ESRC research grant (R000222978) awarded to R. Russo. This study is based in part on N.M.'s doctoral thesis. We thank the members of the Memory Club of the Department of Psychology of the University of Essex for the useful discussions about the theoretical issues raised in the paper. Correspondence should be addressed to R. Russo, Department of Psychology, University of Essex, Wivenhoe Park, Colchester CO4 3SQ, England (e-mail: rrusso@ essex. ac.uk). tentional and incidental learning conditions (Greene, 1989) and after focused and divided attention at learning (Russo, Parkin, Taylor, \& Wilks, 1998).

In contrast, Greene (1989) suggested that for cuedmemory tasks (e.g., recognition memory, frequency judgment tasks), which are more sensitive to item information and less sensitive to contextual information, the spacing effect is due to the deficient processing of the second occurrence of massed items. Specifically, he suggested that this deficient processing was the consequence of an increased amount of voluntary rehearsal given to spaced items. This rehearsal account receives support from the absence of spacing effects in a variety of cued-memory tasks after incidental learning (Greene, 1989). However, the rehearsal explanation cannot be the whole story, since spacing effects are also found under incidental learning conditions, where study items are processed semantically (Challis, 1993; Russo, Mammarella, \& Avons, 2002; Russo et al., 1998). For example, Challis demonstrated the presence of a robust spacing effect for target words in a frequency judgment task after incidental encoding promoting semantic analy sis of target words. On the other hand, no spacing effect was detected after shallow encoding tasks that focused attention on the graphemic features of the target words. On the basis of these and other findings, like the absence of semantic priming after orthographic analysis of words (Smith, Theodor, \& Franklin, 1983), Challis suggested that semantic priming underlies the spacing effect in cued-memory tasks. In a massed presentation, the first occurrence of an item semantically primes its immediate successor, thus leading to a reduction in its semantic processing. Since semantic priming operates only at short lags (Kirsner, Smith, Lockhart, \& King, 1984), there is 
less semantic priming on the second occurrence of a spaced item. Thus the semantic processing directed at spaced items is greater than that for massed items, giving rise to the spacing effect.

A central implication of the semantic priming account of the spacing effect in cued-memory tasks is that this effect should not occur with nonsense target stimuli that do not have a semantic representation in memory. However, contrary to this prediction, it has now been clearly demonstrated that spaced nonsense stimuli are better remembered than massed stimuli in different cued-memory tasks. Cornoldi and Longoni (1977) found a significant spacing effect in a forced-choice recognition memory task using nonsense shapes as targets. Using a yes/no recognition test, Russo et al. (1998) obtained significant spacing effects using unfamiliar faces, and Russo and Mammarella (2002) and Russo et al. (2002) obtained spacing effects with nonwords under learning conditions that discouraged semantic processing. Since the semantic priming hypothesis cannot account for these results, Russo and colleagues argued that short-term perceptual priming gives rise to the spacing effect in cued-memory tasks for unfamiliar targets. They suggested that when items are massed at study, the first occurrence of an item primes and hence reduces perceptual processing of the second occurrence. Given that short-term perceptual priming effects fall off rapidly with lag (McKone, 1995; McKone \& Dennis, 2000; Russo et al., 2002), it follows that more extensive perceptual processing is given to the second occurrence of spaced items relative to that given to massed items. Hence nonsense items with massed presentation receive less extensive perceptual processing than spaced items, and, consequently the retrieval of such items is impaired in cued-memory tasks.

In support of this view, Russo et al. (2002) showed that changing the font between occurrences of repeated nonwords at study significantly reduced the spacing effect in recognition memory. Moreover, at short lags the same manipulation reduced the short-term perceptual repetition priming effect for both words and nonwords in a lexical decision task. On the other hand, changing the font at study did not reduce the spacing effect in a recognition memory task for target words (see also Hintzman, Block, \& Summers, 1973), as predicted by Challis's (1993) semantic priming account.

Evidence supporting the claim that changing the perceptual characteristics at study reduces the spacing effect is currently restricted to several studies of nonword recognition using a yes/no paradigm. It is important therefore to extend the investigation of priming effects for unfamiliar nonsense stimuli to a wider variety of stimuli and to different types of cued-memory tasks. Here, the spacing effect was studied using unfamiliar faces in a recognition memory paradigm (Experiments 1, 3, and 4) and a frequency judgment task (Experiment 2).

There is relatively little evidence available on shortterm repetition priming of unfamiliar faces. Most stud- ies of repetition priming for faces have used the longterm repetition paradigm, in which target stimuli are presented during an initial phase and the same stimuli recur in a later test phase. With tasks such as familiarity decision or naming of familiar faces, long-term repetition priming is strong (e.g., Bruce \& Valentine, 1985; Ellis, Young, \& Flude, 1990). However, with unfamiliar faces, for which the range of tasks is more restricted, much less repetition priming, if any, is found (e.g., Ellis et al., 1990; Goshen-Gottstein \& Ganel, 2000). One theoretically important manipulation is to vary the face pictures between study and test. Many studies of familiar faces have shown that priming decreases when the study and test stimuli differ because of a change of viewpoint (e.g., Bruce \& Valentine, 1985; Ellis, Young, Flude, \& Hay, 1987) or picture format (Bruce, Burton, Carson, Hanna, $\&$ Mason, 1994). A reduction in priming with viewpoint changes between study and test has also been found for unfamiliar faces (e.g., Goshen-Gottstein \& Ganel, 2000), although one study reported a similar amount of reaction time facilitation from identical and changed-viewpoint pictures across multiple repeated presentations (Hay, 2000). This exception aside, pose changes between study and test may account for some failures to find evidence of priming for unfamiliar faces (e.g., Campbell \& DeHaan, 1998). With respect to short-term repetition priming, Bentin and Moscovitch (1988) found a reliable priming effect with unfamiliar faces using a structural discrimination task. This priming effect was smaller and less durable than that observed with familiar faces, and no facilitation was observed at lags greater than zero. To our knowledge, no study has yet reported the effect of pose change on short-term repetition priming with unfamiliar faces. We therefore investigated the effect of pose change on short-term repetition priming of unfamiliar faces in Experiment 1.

We expected that changing the pose between repeated presentations at study would lead to a decrease in the spacing effect, extending the repetition priming argument proposed for nonword stimuli as follows. Consider first the case where identical stimuli (same face, same pose) are repeated. For massed presentation, where the same face is immediately repeated in the same pose, the perceptual mechanisms needed to identify the face on its second presentation will already be activated or primed by prior presentation of the identical stimulus. In contrast, for spaced presentations, the perceptual mechanisms activated by the first presentation of a face will no longer be active when the face is presented again. The reduction in perceptual processing of the second occurrence with massed presentation gives rise to the spacing effect. Consider now the case where the pose is changed between two massed presentations of the same face. These two presentations will now draw on different perceptual mechanisms, and so there will be less evidence of perceptual priming between the first and second presentations, and consequently relatively more processing 
of the second presentation. Thus there will be a reduction in the spacing effect when the pose changes during study.

In principle we would expect that recognition accuracy for the two spaced conditions with same and different poses at study to be approximately equal, because both occurrences receive full (unprimed) perceptual processing. However, the pose manipulation at study (same vs. different) necessarily imposes differences between stimulus conditions that may affect the overall level of recognition performance. Thus, although changing the pose of the second occurrence at study may ensure that this item receives more complete perceptual processing with massed presentation, thus reducing the spacing effect, this should not be taken to imply that recognition memory performance for an item repeated in the same pose will necessarily be equivalent to memory for the same item repeated in different poses. Possible reasons for this are discussed below. Thus the strong prediction from our hypothesis is an interaction between pose consistency at study (same/different) and the spacing of presentations, observable as a decrease in the spacing effect in the different pose condition. Superimposed on this may be a main effect of pose manipulation arising from variations in the relationships between the stimuli presented at study and/or at test (see Russo et al., 2002, for a related argument). Any such shift in baseline performance will of course affect the extent to which differences are found between the massed same pose and massed different pose conditions.

\section{EXPERIMENT 1}

The task used to assess perceptual priming in this experiment was the structural discrimination task that Bentin and Moscovitch (1988) successfully employed to assess repetition priming with unfamiliar faces. In this task a series of target faces and nonfaces were presented twice at Lag 0, Lag 2, and Lag 4 and participants were asked to indicate as soon as each item appeared on the screen whether this was a face or a nonface. Bentin and Moscovitch detected a significant short-term repetition priming effect for unfamiliar faces, but only at Lag 0 . According to our hypothesis, in massed presentation for same pose stimuli, repetition priming should reduce the perceptual processing allocated to the second occurrence of a face, ensuring that spaced faces receive more extensive perceptual processing at learning and leading to a memory advantage for spaced items. In Bentin and Moscovitch's study, repeated faces were always shown in the same pose. However, from studies of long-term repetition priming for faces, and by analogy with the results obtained by McKone and Dennis (2000) and Russo et al. (2002) using nonword targets, we would expect a change of pose to reduce repetition priming at short lags and hence to reduce or eliminate the spacing effect. After the structural discrimination task, used to assess the effect of pose change on short-term repetition priming, an unex- pected recognition memory test was given to assess the impact of changing pose on the spacing effect.

\section{Method}

Participants. Eighteen Italian students from different Italian Universities took part in this study.

Design. A $2 \times 2 \times 3$ repeated measures design was used, with items of both structural status (faces and nonfaces) repeated in the same pose (either full-full or 3/4-3/4) or in different poses (either full-3/4 or 3/4-full) at three different lags (i.e., 0, 2, and 4).

Materials. Eighty-four monochrome male faces were used as baseline and target stimuli in this experiment. These were selected and downloaded from the online databases of the University of Stirling and of the University of Cambridge. All selected faces had neutral expressions. And none of them had glasses, facial hair, or other distinctive features. Faces were displayed on a homogeneous ground after background details and clothing were eliminated. The 84 monochrome nonfaces were constructed by switching two or three facial features (e.g., eyes, nose, and mouth) of male faces drawn from the same sources but different from those displayed as faces. The faces were scrambled using a dedicated software. Figure 1 shows examples of the faces and nonfaces in each of the poses used in the experiment. All the stimuli were presented on a Macintosh computer.

The 84 faces were divided into two sets. Forty-eight faces were used in the baseline condition and were presented only once. They were arranged in 24 pairs so that 24 Lag 0 baseline trials were constructed. The remaining 36 faces were used as targets, of which 12 were repeated at $\operatorname{Lag} 0,12$ at $\operatorname{Lag} 2$, and 12 at $\mathrm{Lag} 4$. The response times used to assess the priming effect were measured on the probe trials for the target and baseline paired stimuli. Each target set and the baseline items were further subdivided in order to have the same number of items assigned to the different prime-probe pose combinations (i.e., full-full, 3/4-3/4, full-3/4, and 3/4-full). The same procedure was also used for the 84 nonfaces. The assignation of items to the baseline and target conditions occurred randomly and was repeated nine times, leading to the creation of nine different lists. Each list was used twice across participants. An additional set of two faces and two nonfaces were chosen as filler items (with the same general characteristics as the targets). These fillers were repeated twice at Lag 0 and were placed at the beginning and the end of the list. Overall, each list was 200 items long. Faces and nonfaces were pseudorandomly intermixed within each list.

By definition, probe trials in massed conditions are always preceded by a prime of the same structural class (i.e., Face A-Face A or Nonface B-Nonface B). The same relation was preserved in the baseline condition, where the probe was always preceded by an unrelated face or nonface (Face C-Face D or Nonface F-Nonface G). Likewise, on spaced trials, each probe was immediately preceded by an item of the same structural class as the probe (Face $\mathrm{H}-\ldots$ -Face X-Face H, or Nonface J- . . -Nonface Y-Nonface J). Moreover, the item preceding a probe trial in massed, spaced, or baseline conditions was presented either in the same pose as the item in the probe trial or in a different pose. This arrangement was used in order to have comparable massed, spaced, and baseline conditions in which the prime and probe trials always shared the same structural status and were presented in either the same or different pose, as required. Any spurious effects on response times to probes due to changes in the preceding item's status or pose would be eliminated. To present faces and nonfaces in the above way, strict control of the presentation sequence was necessary. This was achieved by using two templates specifying 64 trials. One template was used to determine the beginning and the end of the list, while the other template determined the sequence for the middle section.

At the end of the structural discrimination task, during the retention phase, participants were engaged in a graphemic distractor task 
A)

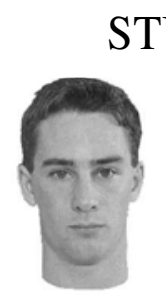

STUDY

TEST
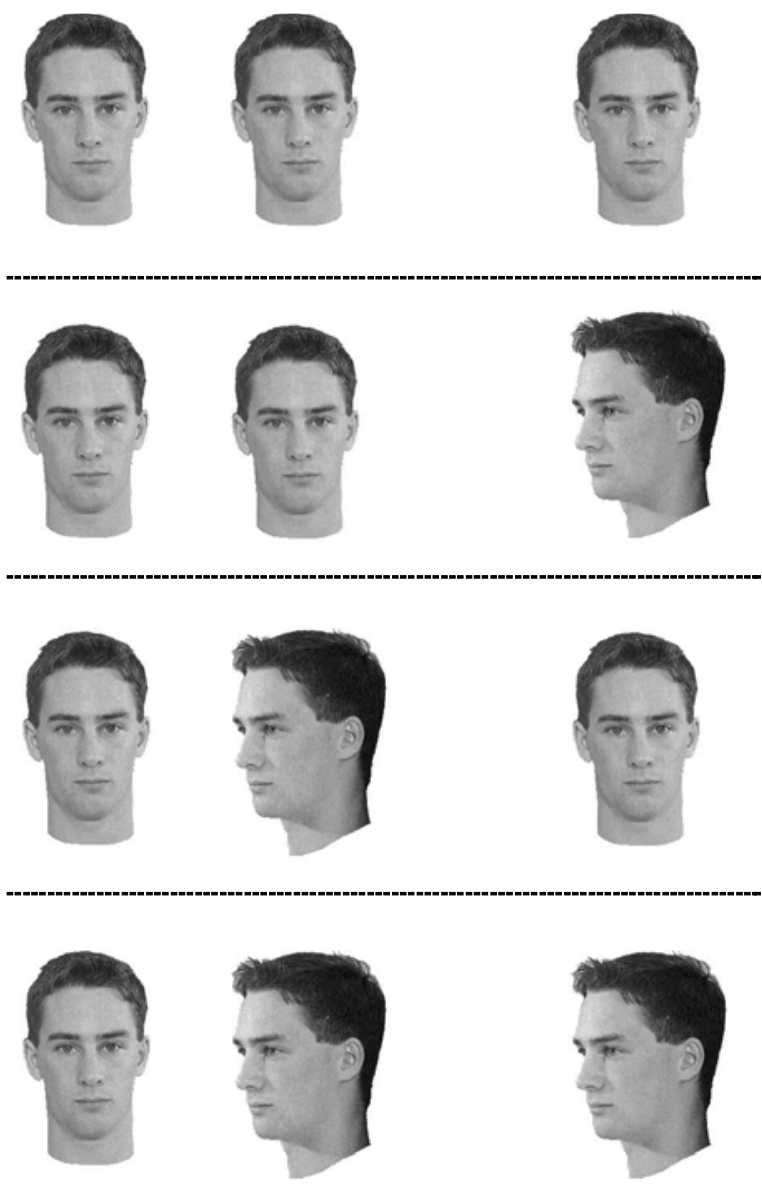

B)

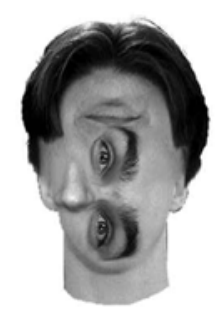

Figure 1. (A) Examples of the face poses used at study and test (full and three-quarter views) in Experiments 1, 2, and 3. (B) Example of the nonfaces used in Experiment 1 in full view.

in which they were asked to count the number of ascending and descending letters in a sequence of words. Finally, participants performed an unexpected recognition memory task only for the unfamiliar faces. The test list consisted of 48 faces presented in random order (e.g., the 36 unfamiliar faces repeated twice during the structural discrimination task and 12 foils). The foils were chosen with the same general characteristics as the targets. The order of presentation of test items was kept constant across all participants.
Procedure. Participants were tested individually in a single 30-min session. In the first part of the experiment, participants completed the structural discrimination task. Each item (face or nonface) was presented centrally on the screen for $4 \mathrm{sec}$ and was then removed. The screen remained blank for $2 \mathrm{sec}$ until the next trial began. To respond, participants pressed one of two keys of a button box connected to a Macintosh computer, using their preferred hand for a face decision and the other hand for a nonface decision. Participants were told to respond as quickly and accurately as possible. If they did not respond within the $4 \mathrm{sec}$ during which stimuli were displayed, the next trial began. The structural discrimination task was preceded by a practice using 10 faces and 10 nonfaces. The experimental list was then presented in one block of 200 trials. Following a 5-min filled retention interval, participants received the unexpected recognition memory test. Faces were shown on the computer screen singly until a response was made. For each face presented at test, participants had to press a key marked "yes" if they remembered having experienced the face during the discrimination task or the key marked "no" if they could not remember having experienced the face during the discrimination task. Half of the participants saw the test faces presented in full pose, and the other half saw the faces presented in three-quarter view.

\section{Results and Discussion}

Structural discrimination task. Incorrect responses to probe trials were excluded from the analysis. Any response times that were slower than $3.5 \mathrm{sec}$ were considered outliers (Goshen-Gottstein \& Ganel, 2000), but in practice all responses were completed before the deadline. Error rates were $0.5 \%$ for faces and $0.6 \%$ for nonfaces.

Repetition priming was calculated for each participant in each condition as the mean response time to the probe trials for repeated items in each of the three lag conditions $(0,2$, and 4$)$, minus the mean response time to the probe trials for the corresponding baseline condition. The appropriate baseline condition for face or nonface targets, repeated at Lag 0 was selected according to the four prime-probe pose combinations (i.e., full-full, 3/4-3/4, full-3/4, and 3/4-full). The appropriate baseline condition for the items repeated at Lag 2 and Lag 4 had to be selected taking into account the type of item and the pose combination between the item immediately preceding the probe trial and the probe trial itself, as explained above. The full list of conditions with the appropriate baselines is shown in Table 1 .

The mean repetition priming scores, calculated as the difference in reaction times between primed and base-

Table 1

Prime and Probe Trials in the Appropriate Baseline Conditions to Assess the Repetition Priming Effect for Items Repeated in Massed (Lag 0) and Spaced (Lag 2 and Lag 4) for Both Faces and Nonfaces, Experiment 1

\begin{tabular}{lcll}
\hline & Massed & \multicolumn{2}{c}{ Spaced } \\
\cline { 3 - 4 } Baseline & Prime-Probe & Prime . . . Preprobe-Probe \\
\hline Full-Full & Full-Full & Full- $\ldots$ & -Full-Full \\
3/4-3/4 & $3 / 4-3 / 4$ & Full- $\ldots$ & $-3 / 4-3 / 4$ \\
Full-3/4 & Full-3/4 & Full- . . & -Full-3/4 \\
3/4-Full & 3/4-Full & $3 / 4-\ldots$ & -3/4-Full \\
\hline
\end{tabular}

Note-For spaced items the pose of the item immediately preceding the probe trial is also given. 
Table 2

Priming Scores (P) and Standard Errors at Each Lag and Prime-Probe Pose Combination (Same Pose vs. Different Pose) for Faces and Nonfaces, Respectively, Experiment 1

\begin{tabular}{|c|c|c|c|c|c|c|c|c|c|c|c|c|}
\hline & \multicolumn{4}{|c|}{ Lag 0} & \multicolumn{4}{|c|}{ Lag 2} & \multicolumn{4}{|c|}{ Lag 4} \\
\hline & \multicolumn{2}{|c|}{ Same } & \multicolumn{2}{|c|}{ Different } & \multicolumn{2}{|c|}{ Same } & \multicolumn{2}{|c|}{ Different } & \multicolumn{2}{|c|}{ Same } & \multicolumn{2}{|c|}{ Different } \\
\hline & $\mathrm{P}$ & $S E$ & $\mathrm{P}$ & $S E$ & $\mathrm{P}$ & $S E$ & $\mathrm{P}$ & $S E$ & $\mathrm{P}$ & $S E$ & $\mathrm{P}$ & $S E$ \\
\hline Faces & $64.1 *$ & 9.1 & $7.1 *$ & 2.3 & $27.4 *$ & 8.6 & -8.8 & 5.6 & 5.2 & 5.1 & -9.7 & 4.7 \\
\hline Nonfaces & $44.9^{*}$ & 7.0 & -9.7 & 6.0 & 8.7 & 6.0 & -14.3 & 7.1 & 4.4 & 6.0 & -11.2 & 5.6 \\
\hline
\end{tabular}

Note-Baselines: Faces same pose, $650 \mathrm{msec}$; faces different pose, $653 \mathrm{msec}$; nonfaces same pose, $647 \mathrm{msec}$; nonfaces different pose, $641 \mathrm{msec}$. *Significantly different from baseline; $p<.01$.

line conditions, are presented in Table 2. A three-way within-subjects analysis of variance (ANOVA) including lags (0 vs. 2 vs. 4$)$, target type (faces vs. nonfaces) and pose used in prime and probe trials (same pose vs. different pose) as factors indicated that there was a nonsignificant difference in the overall performance between the face and nonface conditions $[F(1,17)=2.71]$. The main effect of pose was significant $[F(1,17)=$ $\left.68.62, M S_{\mathrm{e}}=885.9, p<.01\right]$, indicating that the priming effect was significantly larger when prime and probe trials were repeated in the same pose. There was also a significant effect of lag $\left[F(2,34)=48.67, M S_{\mathrm{e}}=357.1, p<\right.$ $.01]$, indicating that the size of the repetition priming effect decreased as lag increased $(\operatorname{Lag} 0=26.6, \mathrm{Lag} 2=$ 3.3 , Lag $4=-2.8)$. The interaction between target type and pose was not significant $[F(1,17)=0.30]$, indicating a similar reduction in the repetition priming effect for both faces and nonfaces when items were repeated in a different pose. There was also a nonsignificant interaction between target type and lag $[F(2,34)=2.72]$, indicating a comparable reduction in the size of the repetition priming effect for both faces and nonfaces as lag increased. However, the interaction between pose and lag was significant $\left[F(2,34)=36.49, M S_{\mathrm{e}}=208.2, p<.01\right]$, indicating that the effect of changing poses between prime and probe trials was more pronounced at shorter lags $[\operatorname{Lag} 0, t(17)=9.62, p<.01 ; \operatorname{Lag} 2, t(17)=5.86, p<$ $.01 ; \operatorname{Lag} 4, t(17)=4.19, p<.01]$. Finally, the three-way interaction was not significant $[F(2,34)=0.77]$, indicating that the pose $\times$ lag interaction was not modulated by the type of target variable (i.e., faces vs. nonfaces).

Multiple $t$ tests were used to evaluate the significance of priming effects at each combination of lag and pose condition for both faces and nonfaces; results are summarized in Table 2. Because of the relatively large number of tests for each type of stimulus (i.e., faces and nonfaces), the $\alpha$ level for each test was held at .01. The repetition priming effect was largest for faces repeated in the same pose at Lag 0. Priming was much smaller but still significant for same pose faces at Lag 2. For faces repeated in different poses, a significant priming effect was found for Lag 0 , but this was much smaller than the priming found for same pose faces at Lag $0[t(17)=6.37$, $p<.01]$. Thus changing the pose between repetitions eliminated most of the repetition priming effect for unfamiliar faces. For nonfaces, repetition priming was found only when the same pose was repeated at Lag 0 .
The results of the structural discrimination task revealed a clear pattern in the repetition priming effect for unfamiliar faces and nonfaces. A strong short-term priming effect was found, but it decayed rapidly, and it was sensitive to a change of pose. When the pose did not change between prime and probe, significant repetition priming effects were found at Lag 0 and Lag 2 for faces, but only at Lag 0 for nonfaces. These results are consistent with Bentin and Moscovitch's (1988) study that reported significant short-term repetition priming for faces and nonfaces only at Lag 0 (the subsequent lag used in that study was Lag 4). For both faces and nonfaces, as predicted, a change of pose brought about a marked decrease in repetition priming relative to the same pose conditions.

This is the first study showing that short-term repetition priming for faces is highly sensitive to a change of pose between prime and probe trials. More generally, these results support other studies of short-term repetition priming for novel and unfamiliar materials (e.g., McKone \& Dennis, 2000; Russo et al., 2002) in showing that perceptual characteristics of the stimuli are critical for short-term repetition priming. According to our hypothesis, the reduction in priming in the different pose condition should lead to a reduction in the spacing effect in recognition memory, to which we now turn.

Recognition memory and spacing effects. Participants performed the unexpected recognition memory test only on unfamiliar faces; the results are presented in Table 3. All statistical analyses were conducted on $d^{\prime}$ scores, using the correction factor suggested by Snodgrass and Corwin (1988). The main analysis was a 3 (Lag 0 vs. Lag 2 vs. Lag 4) $\times 2$ (pose: same at study vs. different at study) within-subjects ANOVA on $d^{\prime}$ scores. There was no significant main effect of pose $[F(1,17)=$ $3.15]$. There was a significant effect of lag $[F(2,34)=$ $\left.8.08, M S_{\mathrm{e}}=0.14, p<.01\right]$, indicating that spaced items were better remembered than massed items $($ Lag $0=$ $1.45, \operatorname{Lag} 2=1.72, \operatorname{Lag} 4=1.77)$. This was coupled with a significant interaction $\left[F(2,34)=9.29, M S_{\mathrm{e}}=0.12, p<\right.$ $.01]$, indicating a reduction in the spacing effect when faces were repeated in a different pose during study. Pooling together Lag 2 and Lag 4 conditions, the mean difference in $d^{\prime}$ scores between massed and spaced items was 0.60 (the $95 \%$ CI ranged from 0.34 to 0.86 ) when the pose was kept constant between repetitions, but the difference between massed and spaced items was zero (the $95 \% \mathrm{CI}$ ranged from -0.23 to 0.23 ) when faces were re- 
Table 3

Proportions (PC) and Standard Deviations of Faces Correctly Recognized as Old (Hits) According to Lag, New Items Recognized as Old (False Alarms; FA), and $d^{\prime}$ Scores for Faces Repeated in the Same and Different Pose During Incidental Learning

\begin{tabular}{|c|c|c|c|c|c|c|c|c|c|c|c|c|c|c|}
\hline \multirow[b]{2}{*}{ Pose of Repetitions } & \multicolumn{2}{|c|}{ Lag 0} & \multicolumn{2}{|c|}{ Lag 2} & \multicolumn{2}{|c|}{$\operatorname{Lag} 4$} & \multicolumn{2}{|c|}{ FA } & \multicolumn{2}{|c|}{$d^{\prime} \operatorname{Lag} 0$} & \multicolumn{2}{|c|}{$d^{\prime} \operatorname{Lag} 2$} & \multicolumn{2}{|c|}{$d^{\prime} \operatorname{Lag} 4$} \\
\hline & PC & $S D$ & PC & $S D$ & PC & $S D$ & PC & $S D$ & PC & $S D$ & PC & $S D$ & PC & $S D$ \\
\hline Same at study & .52 & .16 & .75 & .16 & .77 & .15 & .08 & .06 & 1.31 & .38 & 1.89 & .60 & 1.94 & .47 \\
\hline Different at study & .63 & .18 & .63 & .13 & .65 & .09 & & & 1.58 & .57 & 1.56 & .38 & 1.60 & .41 \\
\hline
\end{tabular}

peated in different poses at study. The mean $d^{\prime}$ scores for massed and spaced items were 1.31 and 1.91 , respectively, when the pose was the kept constant at study, and 1.58 and 1.58 when the pose changed between repetitions at learning.

As in previous studies (Parkin, Gardiner, \& Rosser, 1995; Russo et al., 1998), a significant spacing effect was obtained in recognition memory with unfamiliar faces when the same pose was repeated at study. However, the spacing effect disappeared completely when the pose was changed across repetitions. The pose manipulation was also shown to have a strong effect in decreasing (if not quite eliminating) repetition priming under the same conditions. These results provide support for the idea that reduced perceptual processing of the second occurrence of massed items at learning, induced by shortterm perceptual priming, underlies the spacing effect in cued-memory tasks for unfamiliar faces, and more generally for novel materials (Russo et al., 2002). One anomaly in the present findings was that repetition priming in the same pose condition was not confined to Lag 0 but was also found at $\mathrm{Lag} 2$, although considerably weakened. According to our hypothesis, we should therefore be able to detect a weak spacing effect when comparing Lag 2 with Lag 4 in the same pose condition. This lag effect was not significant. Moreover, the lag effect was slightly numerically larger, but not significantly larger, in the same pose than in the different pose condition at study. It is not clear whether this lack of significance is genuine or whether it simply reflects a lack of statistical power because of the relatively small sample tested.

\section{EXPERIMENT 2}

In this experiment, the manipulation of pose was carried out between subjects. One group of participants was presented with target faces that were always repeated in the same pose during study (i.e., both presentations were full or both were 3/4 view). A second group saw the repeated target faces always presented in different poses during learning (i.e., the first occurrence was full and the second was in 3/4 view, or vice versa). Presentation of repeated occurrences of faces at study in different views was expected to lead to a reduction in the spacing effect.

One problem with changing the pose at study is that participants might misclassify the different poses as depictions of different individuals. To estimate the extent of misclassification, we asked participants to indicate for each face, during learning, whether they had already en- countered that face earlier in the sequence either in the same or in a different view. Participants also performed a structural orienting task on each face (i.e., rating each face in terms of length or symmetry). This task immediately followed each recognition decision in the continuous recognition task. The rating task was used to discourage participants from semantically coding target faces (e.g., attributing personality or connotative traits to the presented faces). In addition, this rating task disguised the fact that a recognition test would follow. Finally, after a brief retention interval, participants were given an unexpected recognition memory task to assess their memory for the faces presented during the incidental learning phase.

\section{Method}

Participants. Forty-eight Italian and English students from the Universities of Essex and Padua took part in this study. Twenty-four students were randomly assigned to the same pose at study condition. At test, half of the participants in this group (i.e., 12) saw each face being presented in the same pose used at study, while for the other half the pose used at test differed from the pose used at study. The remaining 24 participants were assigned to the different pose at study condition. At test, for half of the participants (i.e., 12), all faces were presented in full view, whereas the other half of participants saw only the 3/4 view at test. See Table 4 for a summary of the pose conditions used in this experiment.

Materials. Forty faces were divided into four sets (A, B, C, and D) with 8 faces assigned to each of the first three sets and 16 faces to the last set. Faces were assigned to sets randomly. This process was repeated 12 times, leading to the creation of 12 different study lists. Each study list was used twice for both same and different pose at study conditions. The typical study list contained three sets of items (i.e., A, B, and C). Faces from Set A were repeated twice in a massed way ( $\operatorname{Lag} 0)$; faces from Set B were repeated after two intervening items ( $\operatorname{Lag} 2$ ); faces from Set $\mathrm{C}$ were repeated after four intervening items (Lag 4). Massed (i.e., Lag 0), spaced (i.e., Lag 2 and Lag 4), and filler items were pseudorandomly intermixed in each study list. Each study list was made up of 64 occurrences: Eight targets presented twice at Lag 0 , eight targets presented twice

Table 4

Poses Used at Study to Display the Occurrences of the Repeated Massed and Spaced Faces and Pose Used During Test, Experiment 2

\begin{tabular}{clcc}
\hline $\begin{array}{c}\text { Number of } \\
\text { Participants }\end{array}$ & Poses at Study & $\begin{array}{c}\text { Number of } \\
\text { Participants }\end{array}$ & Pose at Test \\
\hline 12 & Full-Full & 6 & Full \\
& & 6 & $3 / 4$ \\
12 & $3 / 4-3 / 4$ & 6 & $3 / 4$ \\
& & 6 & Full \\
24 & Full-3/4 \& 3/4-Full & 12 & Full \\
& & 12 & $3 / 4$ \\
\hline
\end{tabular}


at Lag 2, eight targets presented twice at Lag 4, and eight filler items. Two fillers were repeated in a massed way at the beginning of each study list and two at the end to reduce primacy and recency effects. Two of the other four fillers were repeated in a massed way and two in a spaced way.

Given that participants had to perform two different orienting tasks, each set of faces- A, B, and C-was divided into two subsets of four faces each. The first four items in each subset were presented with a letter "L" next to the first occurrence and with a letter " $\mathrm{S}$ " next to the second occurrence, whereas the four remaining items were presented with an "S" next to the first occurrence and an "L" next to the second occurrence. Each letter corresponded to the performance of a specific orienting task. Additionally, in the different pose at study condition, each set was further divided into two subsets of four items each. The first four items were assigned to full-3/4 presentation - that is, with the first occurrence in full pose and the second one in $3 / 4$ pose. The remaining four items were assigned to the 3/4-full presentation.

The test list contained all the faces from Sets A, B, C, and D arranged in random order for a total of 40 items. The faces not presented at study (Set D) were used as foils in the test list. The order of presentation of faces at test was kept constant for every participant.

Procedure. In the study phase each face was displayed for $7 \mathrm{sec}$ with a $1-\mathrm{sec}$ interstimulus interval (ISI). Participants were first asked to report whether or not they had seen the face earlier in the sequence, either in the same or in a different pose, by pressing the "yes" or "no" key. Immediately after this recognition decision, participants evaluated the face in one of two ways, rating the face for length if the face appeared with the letter " $L$ " next to it, or symmetry if the face appeared with the letter "S" next to it. Both ratings were made on a 3 -point scale $(1=$ low, $2=$ medium, $3=$ high $)$. Participants said their responses aloud and were told that these were recorded; in fact, none were recorded. Participants were also told to respond as quickly and accurately as possible. If they did not respond within the 7-sec period, the next trial began. Two different ratings of the same target, instead of the same rating repeated twice, were used to prevent the participants from basing their responses to the second occurrence of an item on their memory of the first occurrence, since this has been suggested to induce an artifactual spacing effect (Greene, 1989).

During the 5-min retention interval, participants were asked to answer some general knowledge questions. During the recognition memory test, participants were presented with the faces from the test list one at the time until a response occurred. They had to press the key marked "yes" if they remembered having experienced the item during the rating phase or the key marked "no" if they did not. The whole experiment lasted about $20 \mathrm{~min}$.

\section{Results and Discussion}

Continuous recognition task. The percentage of repeated items not recognized during the continuous recognition memory task at learning was $1.04 \%$ at Lag 0 , $0.5 \%$ at $\operatorname{Lag} 2$, and $1.04 \%$ at Lag 4 when faces were repeated at study in the same pose- that is, either full-full or 3/4-3/4. A Friedman's test on these error scores was not significant $\left[\chi^{2}(2)=0.06\right]$. The percentage of repeated items not recognized was $3.1 \%$ at $\mathrm{Lag} 0,3.1 \%$ at $\mathrm{Lag} 2$, and $6.7 \%$ at Lag 4 when faces were repeated at study in a different pose-that is, either full-3/4 or 3/4-full. In this case, too, the pattern of errors did not differ significantly among lags $\left[\chi^{2}(2)=2.65\right]$. A Kruskal-Wallis test showed that more errors were made by the group that saw the faces repeated in a different pose at study $[U=148, p<.01]$.

Although misclassifications were more common in the different pose than the same pose conditions, the very low error rates rule out the possibility that in Experiment 1 misclassification led to the complete elimination of the spacing effect when pose was changed. As a further precaution, any possibility of contamination of the spacing effect was removed by excluding data from target faces that were not recognized correctly in the continuous recognition task. These data are reported below. A full analysis was also conducted including all test items. The results are not reported here, but it gave equivalent results.

Recognition memory and spacing effects. Recognition memory was assessed using $d^{\prime}$ scores calculated as above. The main analysis was a 3 (Lag 0 vs. Lag 2 vs. Lag 4) $\times 2$ (same vs. different pose at study) mixed ANOVA (see Table 5). This analysis showed a significant effect of pose on recognition memory performance $\left[F(1,46)=4.56, M S_{\mathrm{e}}=0.44, p<.05\right]$, indicating better memory discrimination in the same pose at study condition (same pose $=1.16$; different pose $=0.92$ ). There was a significant effect of lag $\left[F(2,92)=22.37, M S_{\mathrm{e}}=0.045\right.$, $p<.01]$, indicating that spaced items were better remembered than massed items $(\operatorname{Lag} 0=0.88 ; \operatorname{Lag} 2=1.09$; Lag $4=1.15)$. Finally, and more interestingly, the interaction was significant $\left[F(2,92)=8.54, M S_{\mathrm{e}}=0.045, p<\right.$ $.01]$, indicating that the spacing effect was larger when there was no change of pose between the two occurrences of the repeated faces at study. The mean difference in $d^{\prime}$ scores between massed and spaced items was 0.39 (the $95 \% \mathrm{CI}$ ranged from 0.27 to 0.51 ) in the same pose at study condition, whereas it was a nonsignificant 0.10 (the $95 \%$ CI ranged from -0.03 to 0.22 ) in the different pose at study condition. When the pose was the same at study, the mean $d^{\prime}$ scores for massed and spaced items were 0.90 and 1.29 , respectively, whereas the corresponding means were 0.86 and 0.95 for the different pose at study condition.

As in Experiment 1, but with a between-subjects manipulation of pose, a clear spacing effect was found when unfamiliar faces were repeated in the same pose at study, but a change of pose at study eliminated this spacing effect.

In the next experiment, we sought to extend the results of Experiments 1 and 2 to a frequency judgment task. To further generalize the results obtained in the present ex-

Table 5

Proportions (PC) and Standard Deviations of Target Faces Correctly Recognized as Old (Hits), False Alarms (FA), and $d^{\prime}$ Scores According to Lag and Pose Conditions, Experiment 2

\begin{tabular}{|c|c|c|c|c|c|c|c|c|c|c|c|c|c|c|}
\hline \multirow[b]{2}{*}{ Pose of Repetitions } & \multicolumn{2}{|c|}{$\operatorname{Lag} 0$} & \multicolumn{2}{|c|}{ Lag 2} & \multicolumn{2}{|c|}{$\operatorname{Lag} 4$} & \multicolumn{2}{|c|}{ FA } & \multicolumn{2}{|c|}{$d^{\prime} \operatorname{Lag} 0$} & \multicolumn{2}{|c|}{$d^{\prime} \operatorname{Lag} 2$} & \multicolumn{2}{|c|}{$d^{\prime} \operatorname{Lag} 4$} \\
\hline & PC & $S D$ & PC & $S D$ & $\mathrm{PC}$ & $S D$ & PC & $S D$ & PC & $S D$ & PC & $S D$ & PC & $S D$ \\
\hline Same at study & .48 & .19 & .62 & .17 & .66 & .19 & .16 & .07 & 0.90 & .36 & 1.23 & .32 & 1.35 & .39 \\
\hline Different at study & .48 & .17 & .52 & .13 & .52 & .15 & .17 & .08 & 0.86 & .52 & 0.95 & .47 & 0.96 & .43 \\
\hline
\end{tabular}


periment, in Experiment 3 we selected a different set of lags-Lag 0 versus Lag 6 instead of Lag 0 versus Lag 2 versus Lag 4.

\section{EXPERIMENT 3}

This experiment examined the effects of spaced repetitions on a frequency judgment test, a cued-memory test that has often been used to test spacing effects for meaningful material (e.g., Challis, 1993; Greene, 1989; Rose, 1980). In this experiment, participants saw unfamiliar faces presented either once or twice during incidental learning. Faces presented twice were repeated at either Lag 0 or Lag 6. The presentation condition (same pose or different pose at study) was manipulated between subjects, as in Experiment 2. At test participants were instructed to try to remember how many times each face had been presented in the study list. As in Experiment 1, it was predicted that the spacing effect would be reduced for repeated faces presented in different poses at study.

\section{Method}

Participants. Forty native Italian and English students from the University of Essex took part in this experiment. Twenty students were assigned to the same pose at study condition, of whom half (10 participants) saw the faces at test in the same pose used at study. The other half saw the test faces in a different pose. The remaining 20 participants were assigned to the different pose at study condition. Half of the participants in this group saw the faces in full pose at test, and the remaining half saw the $3 / 4$ view at test.

Materials. The materials from Experiment 2 were again used here. Forty faces were allocated to four sets (A, B, C, and D). The 16 faces in Set A were assigned to the single presentation. Sets B and $\mathrm{C}$, comprising 8 faces each, were assigned to massed and spaced presentation, respectively. The 8 faces in Set D were only used as foils in the test list. Faces were assigned to each set randomly. This process was repeated 10 times, leading to the creation of 10 different study lists. Each study list was used twice for both the same and different pose at study groups. Single, massed, spaced, and filler items were pseudorandomly intermixed in each study list. Each study list was made up of 56 occurrences: 16 targets presented once, 8 targets presented twice at Lag 0,8 targets presented twice at Lag 6 , and 8 filler occurrences ( 4 in a full pose and 4 in a $3 / 4$ pose). Two fillers items were repeated in a massed way at the beginning of each study list and 2 at the end to reduce primacy and recency effects. Since participants were required to perform two orienting tasks on each repeated item at study, the same arrangement used in Experiment 2 was also used in Experiment 3 to subdivide sets of faces with respect to the type of orienting task to be performed on each occurrence during incidental learning. The same arrangement applied to the once-presented items, except that in this case, 8 items were assigned to one rating task and the remaining 8 items to the other rating task. Finally, the test list contained all faces from Sets A, B, C, and D in random order for a total of 40 items. The order of presentation was kept constant across all participants.

Design and Procedure. Presentation conditions (i.e., items seen once at learning; items seen twice at learning at either Lag 0 or Lag 6, and items not experienced at study) were manipulated within subjects. The manipulation of face pose was a between-subjects factor with two levels (same vs. different pose at study). The dependent variable was mean frequency estimate. Participants were shown a sequence of faces. Each face was presented for $4 \mathrm{sec}$ with an ISI of $1 \mathrm{sec}$. Participants were asked to perform a rating task on each face, as in Experiment 2. After the 5-min retention interval, during which participants were asked to answer some general knowledge questions, they were engaged in a frequency judgment memory task. Participants were reminded that faces presented in the study list occurred either once or twice. They were asked to try to remember how many times each face had been presented in the study list and to press the " 0 " key if the item had not been presented, " 1 " if the item had been presented once, and " 2 " if the item had been presented twice. The experiment lasted about $20 \mathrm{~min}$.

\section{Results and Discussion}

The mean frequency estimates as a function of pose and repetition conditions are shown in Table 6. The main analysis was a 3 (single presentation vs. Lag 0 vs. Lag 6) $\times 2$ (same vs. different pose at study) mixed ANOVA. This analysis showed that the effect of pose condition on frequency judgment performance was not significant $[F(1,38)=2.22]$. There was, however, a significant effect of presentation conditions $\left[F(2,76)=182.29, M S_{\mathrm{e}}=\right.$ $0.030, p<.01]$, indicating that repeated items were judged as having been experienced more frequently during learning than items presented once (once presented $=$ $0.47 ; \operatorname{Lag} 0=1.01 ; \operatorname{Lag} 6=1.18)$. Most interestingly, the interaction was also significant $\left[F(2,76)=13.51, M S_{\mathrm{e}}=\right.$ $0.030, p<.01]$, mainly indicating that a larger spacing effect occurred when faces were repeated using the same pose as at study. A specific test on repeated items only confirmed that the spacing effect was significantly larger when items were repeated in the same pose at learning, where the difference in frequency estimates was 0.37 (the $95 \%$ CI ranged from 0.28 to 0.47 ), than in the different pose at learning condition where the corresponding difference was -0.03 (the $95 \%$ CI ranged from -0.16 to 0.11$)\left[F(1,38)=24.41, M S_{\mathrm{e}}=0.066, p<.01\right]$. The mean frequency estimates for massed and spaced items were 0.95 and 1.32 , respectively, when the pose was the same at study, whereas these means were 1.07

Table 6

Mean Frequency Estimates and Standard Deviations as a Function of the Pose Used to Display the Occurrences of the Repeated Faces During Incidental Learning and as a Function of the Number of Presentations of Each Target at Study, Experiment 3

Number of Presentations at Study

\begin{tabular}{|c|c|c|c|c|c|c|c|c|}
\hline \multirow[b]{3}{*}{ Pose of Repetitions } & \multicolumn{8}{|c|}{ Number of Presentations at Study } \\
\hline & \multicolumn{2}{|c|}{ Zero } & \multicolumn{2}{|c|}{ One } & \multicolumn{2}{|c|}{ Two (Lag 0) } & \multicolumn{2}{|c|}{ Two (Lag 6) } \\
\hline & $M$ & $S D$ & $M$ & $S D$ & $M$ & $S D$ & $M$ & $S D$ \\
\hline Same pose at study & 0.26 & .11 & 0.49 & .14 & 0.95 & .23 & 1.33 & .20 \\
\hline Different poses at study & 0.24 & .14 & 0.46 & .10 & 1.07 & .21 & 1.04 & .26 \\
\hline
\end{tabular}


and 1.04 for the different pose at study condition. Finally, mean frequency estimates were significantly larger for faces presented once at study $(0.47)$ than they were for foils never seen during learning $(0.25)[F(1,39)=$ $\left.87.55, M S_{\mathrm{e}}=0.011, p<.01\right]$.

In this experiment participants were not asked to perform a continuous recognition task before the rating phase. Thus, we did not have any direct data on the ability to recognize, during learning, the second occurrence of a previously seen face as being a repetition. However, the results showed that repeated faces whose pose changed between repetitions at learning were judged to have occurred more frequently than were single presented faces ( 1.07 vs. 0.46 , respectively), indicating that participants were able to detect repetitions displayed in a different pose. Thus the lack of a spacing effect in the different pose condition cannot be explained by misclassification of repeated faces.

The results of Experiment 3 provide further evidence for the occurrence of spacing effects in cued-memory tasks for unfamiliar faces, extending these results to a frequency judgment task. As in the previous two experiments, this spacing effect was eliminated when repeated faces were presented in different poses at study.

The interaction between spacing and pose condition. In Experiments 1-3 we have shown a consistent spacing effect for faces repeated in the same pose. After massed presentation of items, recognition is much poorer than following spaced presentation. Our explanation is that this is the result of deficient processing of the second of two massed stimuli, since the perceptual mechanisms engaged by the first presentation are still active. Thus perceptual processing of the second presentation does not proceed in full, leading to an impairment in later recognition. With spaced presentations, the perceptual processes engaged by the first presentation are no longer active when the second occurrence is presented. Hence on the second presentation full perceptual processing takes place, and subsequent recognition is enhanced (relative to the massed condition) by the increased perceptual processing the item has received. If we consider only the perceptual processing of the items at study, we should expect this to be roughly the same for spaced items in the same pose and different pose conditions, whereas for massed items in the different pose condition, recognition should be roughly equal to that in the spaced conditions and superior to that in the massed same pose condition. Therefore, other things being equal, we should in principle expect an increase for massed different pose items over massed same pose items. However, the interaction we observed between spacing and pose conditions did not conform to this pattern. The reason for this is that changing the stimuli at study may affect the overall level of performance in several ways, so that the stable recognition level achieved in the different pose at study condition may not equate to spaced recognition found in the same pose at study condition. Generally, in all three experiments, recognition was lower for spaced (and massed) presentations when the pose changed at study than for spaced presentations with the same pose at study $(t \mathrm{~s}>2.37, p \mathrm{~s}<.05$; Tables 3,5 , and $6)$. For this reason our emphasis throughout has been on the comparison of spacing effects across pose conditions.

In an earlier paper reporting experiments with nonwords, we argued that one important difference between the presentation conditions was that in the study condition, where the second occurrence of an item differs in form from the first, at least one of the presented occurrences will always match the test item exactly. In contrast, where the two occurrences at study are perceptually identical, either both or neither of the study items will match the test item exactly. Thus overall recognition performance may depend on study-test homogeneity (i.e., if the perceptual form of targets at study matches the form at test), as well as on spacing and the manipulation of exemplars. Within the paradigm we have explored, in which there are just two alternative forms of each stimulus, it is impossible to control perfectly for study-test homogeneity. However, a close inspection of the conditions where stimuli are repeated in the identical form at study can indicate whether study-test homogeneity affects recognition performance. In the previous study, using nonwords, we found evidence that the homogeneity of study and test stimuli (same or different fonts) did influence performance. For items repeated in the same font at study, recognition performance was consistently better when the study and test fonts matched than when they did not. This was shown in two independent experiments (Russo et al., 2002). Critically, study-test homogeneity did not interact with the effect of spacing. Thus for the studies using nonwords, the extent to which study and test fonts matched may have affected the absolute level of recognition performance, but it did not compromise the spacing effect, which can be explained only in terms of the homogeneity of the items at study.

With respect to the present studies of unfamiliar faces, repeated in the same pose at study, the effect of study-test homogeneity on recognition accuracy was much less marked. In Experiment 1, the mean $d^{\prime}$ scores for massed and spaced items were 1.31 and 1.81 , respectively, when items were repeated in the same pose used at test, and 1.30 and 1.86 when the pose differed between study and test. ${ }^{1}$ In Experiment 2, the scores for same pose massed and spaced items, respectively, were 0.83 and 1.29 when the pose was the same at study and test, and 0.95 and 1.29 when the pose differed at test. In both experiments, when items were repeated in the same pose during study, overall recognition accuracy was unaffected by the similarity of the study and test targets $(F<1)$, and the large spacing effect found with faces repeated in the same pose did not interact with study-test homogeneity $(F<1)$. Thus both experiments failed to show an effect of study-test homogeneity on recognition memory, suggesting that study test homogeneity is not responsible for the difference in performance between spaced same pose and different pose conditions. For Experiment 3, in which the task was fre- 
quency judgment, the results were different. The mean frequency estimates for massed and spaced items were 1.09 and 1.40, respectively, when the pose was the same between study and test, and 0.81 and 1.25 , respectively, when the pose was the same at study and different at test. Here there was an effect of study-test homogeneity, with superior recognition for repeated items presented in the same pose at study and at test $(1.25 \mathrm{vs} .1 .03)[F(1,18)=$ $\left.5.81, M S_{\mathrm{e}}=0.050, p<.05\right]$. Again, the size of the spacing effect did not differ significantly between the two pose conditions $[F(1,18)=1.9]$.

Thus, in these three experiments using unfamiliar faces, the evidence on the influence of study-test homogeneity on overall recognition was mixed. There is no compelling case for claiming that differences in baseline performance may be explained by study-test homogeneity, although it cannot be ruled out in all cases. Importantly, in all three cases there was no interaction between study-test homogeneity and the spacing effect. Therefore, the absence of the spacing effect when the pose is changed at study cannot be explained by a confound with study-test homogeneity.

One way to circumvent the problem of study-test homogeneity is to present target faces at test using a third, new pose that has not been previously used during learning. In this way the pose at test is always different from those used both in the same and in the different pose conditions at study. Experiment 4 set out to do this. During the incidental learning phase a series of target faces were repeated at different lags either in the same or in a different pose (same vs. different pose was manipulated within subjects). The poses used at study were full (with a hat covering the hair) and 3/4 (without hat). At test, participants were asked to perform a yes/no recognition memory test on a series of old and new faces, where all faces were presented using a new pose (i.e., full face without hat, so that the hair could be seen). Once again, our strong prediction was that a strong spacing effect would be found when the same pose was repeated at study, but a much weaker spacing effect would be found when different poses were shown at study.

Although in previous experiments the absence of a spacing effect in the different pose condition was always accompanied by a general decrease in recognition performance, in the present study we expected performance in the different pose conditions to improve. This could arise in two ways. First, the introduction of a new test item could eliminate a possible confound between pose condition and study-test homogeneity, although the evidence for any study-test homogeneity effects with faces is not strong. A second mechanism whereby introducing a novel test item might increase performance on different pose conditions is that providing variation in stimuli during study might increase generalization to new items at test. ${ }^{2}$ In either case, our aim was to show that the spacing effect can be manipulated by controlling the perceptual characteristics of repeated items during study and that this effect persists when recognition levels remain the same for spaced same pose and different pose conditions.

\section{EXPERIMENT 4}

\section{Method}

Participants. Twenty-two students from various Italian universities and from University of Essex took part in this experiment. None of them had taken part in the previous experiments.

Materials. Thirty-six unfamiliar faces were used. These faces were divided into three sets (A, B, and C) each comprising 12 faces. Items were randomly assigned to each set. In order to create 11 different study lists, this process was repeated 11 times. Each study list was used twice. The typical study list contained two sets of items (A and B). Items from Set A were repeated twice in a massed way (Lag 0), whereas those from Set B were repeated after 6 intervening faces $(\operatorname{Lag} 6)$. The set of items not presented during study (i.e., C) was used to provide the distractor items in the test list. Each set in the study list (A and B) was further divided into two subsets comprising six items each. Six items in each set were randomly assigned to the same presentation condition (i.e., with pose at study being full-full or 3/4-3/4) and six items to the different condition (i.e., with pose at study being full-3/4 or 3/4-full). This applied to both massed and spaced presentations. During learning, faces in full pose were displayed with a (digitally superimposed) hat covering the hair. For the $3 / 4$ pose there was no hat (Figure 2).

The structure of each study list was obtained by repeating a template specifying 37 trials, so that each study list comprised 74 trials. Each template consisted of 6 target faces presented twice at Lag 0 and another 6 target faces presented twice at Lag 6, randomly intermixed, with four fillers at the beginning and four at the end. Five other fillers were presented once throughout the template. Participants performed two different structural orienting tasks on the same target during study, one for each of the two presentations of each target item. Therefore the first three items in each combination of pose condition and lag were presented with a letter "L" next to the first occurrence and a letter " $\mathrm{S}$ " next to the second occurrence, while the three remaining items were presented with an "S" next to the first occurrence and an "L" next to the second occurrence. The presence of different letters next to a face was associated with the requirement to perform different orienting tasks during learning. This procedure was used for both Set A and Set B. A similar arrangement was also applied to the fillers. Finally, the test list contained all 36 faces from the three sets (i.e., A, B, and C) in random order. At test faces were always presented in full pose without a hat.

Design and Procedure. The presentation of study items and the orienting tasks were the same as in Experiment 3. The main difference was that here the pose conditions at study (same vs. different) were manipulated within subjects. The recognition memory test phase was conducted as in Experiments 1 and 2, except that the pose used to display the faces at test was different from any of the poses at study.

\section{Results and Discussion}

The proportions of hits, false alarms, and $d^{\prime}$ scores obtained in Experiment 4 are presented in Table 7. Statistical analyses were conducted on $d^{\prime}$ scores. A 2 (Lag 0 vs. Lag 6) $\times 2$ (pose: same at study vs. different at study) within-subjects ANOVA showed no significant effect of pose on recognition memory performance $(F<1)$. There was a significant effect of lag $\left[F(1,21)=31.34, M S_{\mathrm{e}}=\right.$ $0.043, p<.01]$, indicating that spaced faces were better discriminated than massed items. More importantly, the interaction was significant $\left[F(1,21)=4.61, M S_{\mathrm{e}}=0.087\right.$, $p<.05]$, indicating a larger spacing effect when faces were repeated in the same pose than in different poses during learning. The mean difference in $d^{\prime}$ scores between spaced and massed items was 0.38 when no pose changes occurred at study (the $95 \% \mathrm{CI}$ ranged from 0.21 


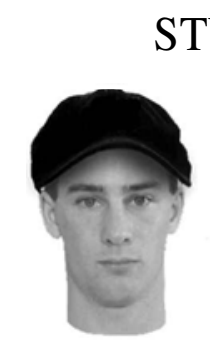

STUDY
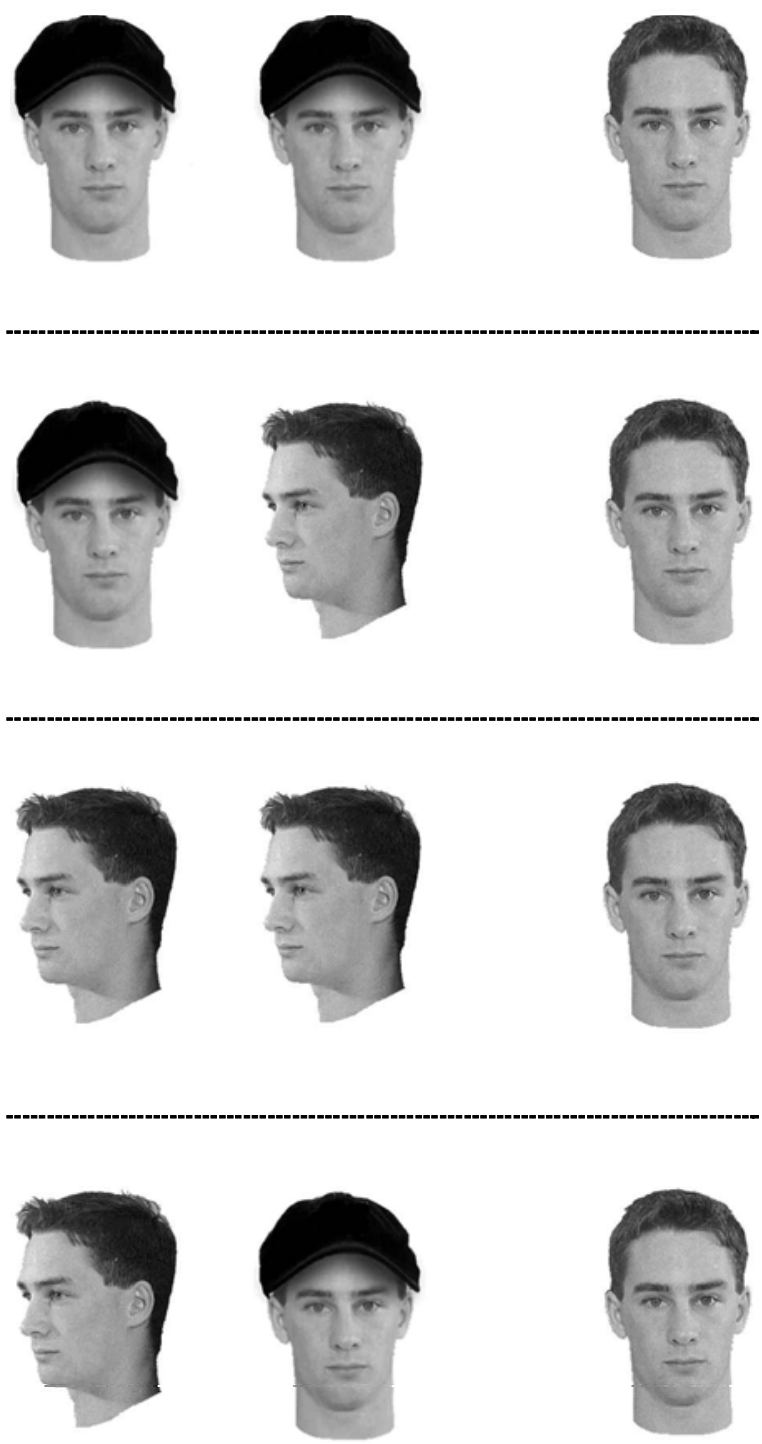

Figure 2. Examples of the poses used at study and test (fullstandard,full-with-hat, and three-quarter views) in Experiment 4.

to 0.55 ), whereas this difference was 0.11 when pose changes occurred at study (the $95 \%$ CI ranged from -0.03 to 0.26 ). A further test showed no effect of pose condition when faces were spaced $[t(21)=0.07]$. On the other hand, massed faces displayed in different poses at study were better remembered than massed faces displayed in the same pose at study $[t(21)=2.72, p<.05]$.

In summary, the results of Experiment 4 showed once again that the spacing effect for unfamiliar faces in a yes/no recognition memory task was reduced and almost eliminated when faces were repeated using different poses during learning. Moreover, with the use of a new test pose that differed from both study poses, the level of spaced recognition performance was equivalent under both pose conditions. Hence the reduction in the spacing effect reported in previous experiments was not an artifact of lower recognition performance in the different pose conditions.

\section{EXPERIMENT 5}

In a previous study of nonwords, we demonstrated that the size of the spacing effect was reduced when target items were repeated in different fonts during study (Russo et al., 2002). We also showed that changing font reduced the extent of repetition priming at Lag 0 in a lexical decision task. However, analogous to the results of Experiments $1-3$, we found that in one of the two reported experiments using nonwords, recognition levels were lower for spaced items when these were presented in different fonts at study. It is therefore important to show that for nonwords, as for faces, a reduction in the spacing effect will be found when recognition levels are equated for the spaced conditions. Experiment 5 aimed to extend the results obtained in the previous experiment to nonwords using the same experimental design. The main manipulation was a change of type font that changed the perceptual characteristics, but not the identity, of the target items at study. In the same font condition, repeated items were displayed twice in the same font at study (either Amazon or Trebuchet), whereas in the different font condition, repeated items were displayed in different fonts (Amazon and then Trebuchet, or vice versa). At test, both targets and foils were displayed using a new font (Helvetica). With this manipulation we expected that recognition memory of spaced nonwords displayed in different fonts at study would be similar to spaced nonwords repeated in the same font during learning. Based on the perceptual priming account of spacing effects for novel or unfamiliar materials, we expected that the reduction in the spacing effect would be found in the different font condition. With respect to the priming account of spacing effects, it is relevant to note that the font manipulation used at learning was shown by Russo et al. (2002) to

Table 7

Proportions (PC) and Standard Deviations of Faces Correctly Recognized as Old (Hits), False Alarms (FA), and $d^{\prime}$ Scores According to Lag and Pose Conditions, Experiment 4

\begin{tabular}{|c|c|c|c|c|c|c|c|c|c|c|}
\hline \multirow[b]{2}{*}{ Pose of Repetitions } & \multicolumn{2}{|c|}{ Lag 0} & \multicolumn{2}{|c|}{ Lag 6} & \multicolumn{2}{|c|}{ FA } & \multicolumn{2}{|c|}{$d^{\prime} \operatorname{Lag} 0$} & \multicolumn{2}{|c|}{$d^{\prime} \operatorname{Lag} 6$} \\
\hline & $\mathrm{PC}$ & $S D$ & $\mathrm{PC}$ & $S D$ & $\mathrm{PC}$ & $S D$ & $\mathrm{PC}$ & $S D$ & $\mathrm{PC}$ & $S D$ \\
\hline Same at study & .58 & .15 & .72 & .19 & & & 1.118 & .33 & 1.500 & .37 \\
\hline Different at study & .68 & .17 & .71 & .08 & & & 1.320 & .29 & 1.434 & .36 \\
\hline
\end{tabular}


affect short-term nonword repetition priming in much the same way as the pose manipulation affected shortterm priming for unfamiliar faces in Experiment 3. In particular, changing the font between prime and probe trials depressed repetition priming for nonwords repeated at Lag 0 .

\section{Method}

Participants. Twenty students from University of Essex took part in this experiment. All participants were native English speakers.

Materials. Ninety-six nonwords were used. These items were selected from a larger sample of nonwords that had been rated by an independent group of people on pronounceability and on their association value. The selected nonwords did not have strong associations to English words, but they were quite easy to pronounce. These nonwords were randomly assigned to three sets (A, B, and C) of 32 nonwords. In order to create 10 different study lists, this process was repeated 10 times. Each study list was used twice. Each study list contained two sets of items (i.e., A and B): Items from Set A were repeated twice in a massed way $(\operatorname{Lag} 0)$, while those from Set B were repeated after six intervening nonwords (Lag 6). The set of items not presented during study (i.e., C) was used to provide the foils for the test list. Each set in the study list (i.e., A and B) was further divided into four subsets comprising eight items each. Thus eight items in each set were randomly assigned to the Amazone-Amazone presentation condition, eight items to the Trebuchet-Trebuchet condition, eight items to the AmazoneTrebuchet condition, and eight items to the Trebuchet-Amazone condition. This applied to both massed and spaced presentations.

The structure of each study list was obtained by repeating a template twice. This template was 80 trials long. Sixteen targets were presented twice at Lag 0,16 targets were presented twice at Lag 6, and four fillers appeared at the beginning of the template and four at the end. Four other fillers were repeated twice in a spaced way. Massed and spaced items were randomly intermixed in the template. Therefore, each study list was made up of 160 nonword presentations.

Graphemic orienting tasks were used to minimize the opportunity of some form of semantic encoding of targets. On each of the two displays of target or repeated filler items, a different graphemic orienting task was performed. This was indicated by presenting an asterisk $(*)$ next to one presentation of the target, and in the other case presenting the target alone. The order of orienting tasks across repetitions was counterbalanced across targets. Finally, the test list contained all 96 nonwords from the three sets (A, B, and C) arranged in random order. All test items were displayed in 65 Helvetica medium font.

Design and Procedure. A two-factor within-subjects design was used. Repetition of target nonwords during study had two levels (massed vs. spaced, i.e., Lag 0 vs. Lag 6). The font manipulation also had two levels (i.e., items repeated in the same font vs. different fonts at study).

During the incidental learning phase, each participant saw a sequence of nonwords on a computer screen. Each item was displayed for $3 \mathrm{sec}$ with a 1-sec ISI. Participants were told that if an item appeared with an asterisk next to it (“*”), they had to count the number of letters that extended above or below the main body of the item (e.g., letters such as "t" or "g"). Otherwise they had to count the number of letters with enclosed parts (e.g., letters such as "d" or "b").

Participants said their responses aloud and were told that these were recorded, but in fact none was recorded. During the 5-min retention interval they were asked to perform a digit cancelation task. At test, participants were asked to perform a yes/no recognition memory test. Old and new nonwords were presented in random order. Items at test were always presented in Helvetica. Each item remained displayed on the screen until participants responded. They had to press the key marked "yes" if they remembered having seen the nonword during the incidental study phase or the key marked "no" if they could not remember having seen the nonword during the incidental learning phase. The experimental session lasted about $20 \mathrm{~min}$.

\section{Results and Discussion}

Percentages of hits, false alarms, and $d^{\prime}$ scores obtained in Experiment 5 are presented in Table 8. Statistical analyses were conducted on $d^{\prime}$ scores. A 2 (Lag 0 vs. Lag 6) $\times 2$ (font: same at study vs. different at study) within-subjects ANOVA showed the effects of the font and the lag manipulations on recognition memory were not significant $\left[F(1,19)=1.51, M S_{\mathrm{e}}=0.12\right.$, and $F(1,19)=$ $2.95, M S_{\mathrm{e}}=0.06$, respectively]. More importantly, the interaction was significant $\left[F(1,19)=4.75, M S_{\mathrm{e}}=0.04\right.$, $p<.05]$, indicating a larger spacing effect when nonwords were repeated in the same font than in different fonts during learning. The mean difference in $d^{\prime}$ scores between spaced and massed items was 0.19 when no font changes occurred at study (the $95 \% \mathrm{CI}$ ranged from 0.08 to 0.31 ), whereas this difference was zero when font changes occurred at study (the $95 \%$ CI ranged from -0.18 to 0.18 ). Further tests showed that recognition memory for spaced nonwords repeated in the same versus different font at learning did not differ significantly $[t(19)=0.02]$, showing that the manipulation to equate performance in these conditions was successful. On the other hand, massed nonwords displayed in different fonts at study were better remembered than massed nonwords repeated in the same font during learning $[t(19)=2.35, p<.05]$.

In summary, the results of Experiment 5 replicated those obtained in Experiment 4 using nonwords instead of faces as unfamiliar target stimuli. The rationale driving Experiments 4 and 5 was to equate recognition performance in the same and different font spaced conditions, while removing potential confounding effects that could arise from differences in study-test homogeneity. The important result was that when performance was equated in the spaced same font and different font conditions, the spacing effect was eliminated by changing font during study.

Table 8

Proportions (PC) and Standard Deviations of Nonwords Correctly Recognized as Old (Hits), False Alarms (FA), and $d^{\prime}$ Scores According to Lag and Font Conditions, Experiment 5

\begin{tabular}{|c|c|c|c|c|c|c|c|c|c|c|}
\hline \multirow[b]{2}{*}{ Font of Repetitions } & \multicolumn{2}{|c|}{ Lag 0} & \multicolumn{2}{|c|}{ Lag 6} & \multicolumn{2}{|c|}{ FA } & \multicolumn{2}{|c|}{$d^{\prime} \operatorname{Lag} 0$} & \multicolumn{2}{|c|}{$d^{\prime} \operatorname{Lag} 6$} \\
\hline & $\mathrm{PC}$ & $S D$ & $\mathrm{PC}$ & $S D$ & $\mathrm{PC}$ & $S D$ & $\mathrm{PC}$ & $S D$ & $\mathrm{PC}$ & $S D$ \\
\hline Same at study & .41 & .14 & .48 & .17 & & & 0.923 & .24 & 1.116 & .34 \\
\hline Different at study & .48 & .15 & .48 & .16 & & & 1.114 & .35 & 1.113 & .36 \\
\hline
\end{tabular}




\section{GENERAL DISCUSSION}

Overall, the results obtained in five experiments provide support for the view that short-term perceptual repetition priming mediates the spacing effect in cuedmemory tasks for unfamiliar stimuli. On this account, perceptual priming reduces the perceptual processing of the second occurrence of massed items relative to spaced items. Under the assumption that recognition of unfamiliar material relies heavily on perceptual information about target items, then, differences in the amount of perceptual processing between the second occurrence of massed and spaced items at learning provide a basis for the emergence of the spacing effect. Congruent with this view, the present experiments showed that changing the perceptual form between the repetitions at study (1) reduced perceptual repetition priming for faces (for a corresponding result with nonwords see Russo et al., 2002), and (2) in all cases reduced (and in some cases eliminated) the spacing effect in recognition memory and frequency judgment tasks.

As a cautionary note it is important to keep in mind that we found that those conditions that reduced shortterm priming for unfamiliar faces also reduced the spacing effect for these stimuli in cued-memory tasks. Hence we showed that there is an association between shortterm repetition priming and the spacing effect. This does not guarantee that repetition priming mechanisms cause the spacing effect. Nevertheless the reliable reduction in spacing effects whenever a variable affecting repetition priming was manipulated strengthens the possibility that short-term repetition priming is the mechanism underlying the spacing effect in cued-memory tasks for unfamiliar stimuli. Considered in relation to other studies of the spacing effect, the present study demonstrates that a multifactor approach is required to provide a complete account of spacing effects in explicit memory tasks (Challis, 1993; Greene, 1989; Russo et al., 2002).

The results obtained in the repetition priming tasks are also relevant to the theoretical debate about which type of representation supports short-term repetition priming (for a discussion see Bowers, 2000; Tenpenny, 1995). This type of evidence is incongruent with views positing that repetition priming is mainly supported by abstract representations (e.g., Morton, 1979). If abstract codes support repetition priming for unfamiliar faces, the pose manipulation should not affect repetition priming. Rather, the results obtained in Experiment 1 support those episodic views suggesting that short-term repetition priming for unfamiliar faces is supported by new perceptual representations acquired during previous study episodes (e.g., Goshen-Gottstein \& Ganel, 2000; Roediger, Weldon, \& Challis, 1989; Schacter, 1994).

In conclusion, the results obtained in the present study demonstrate the need for a multifactor approach to provide a complete account of spacing effects in explicit memory tasks (Challis, 1993; Greene, 1989; Russo et al., 2002). In particular, the novelty of the present study has been in providing evidence congruent with the view that shortterm perceptual priming underlies the spacing effect in explicit cued-memory tasks for meaningless unfamiliar stimuli like nonwords and unfamiliar faces.

\section{REFERENCES}

Bentin, S., \& Moscovitch, M. (1988). The time course of repetition effects for words and unfamiliar faces. Journal of Experimental Psychology: General, 117, 148-160.

Bowers, J. S. (2000). In defense of abstractionist theories of repetition priming and word identification. Psychonomic Bulletin \& Review, 7, 83-99.

Bruce, V., Burton, M., Carson, D., Hanna, E., \& Mason, O. (1994). Repetition priming of face recognition. In C. Umiltà \& M. Moscovitch (Eds.), Attention and performance XV: Conscious and nonconscious information processing (pp. 179-201). Cambridge, MA: MIT Press.

BRUCE, V., \& VAlEntine, T. (1985). Identity priming in the recognition of familiar faces. British Journal of Psychology, 76, 363-383.

Campbell, R., \& DeHaAn, E. (1998). Repetition priming for face speech images: Speech-reading primes face identification. British Journal of Psychology, 89, 309-323.

Challis, B. H. (1993). Spacing effects on cued-memory tests depend on level of processing. Journal of Experimental Psychology: Learning, Memory, \& Cognition, 19, 389-396.

Cornoldi, C., \& Longoni, A. (1977). The MP-DP effect and the influence of distinct repetitions on recognition of random shapes. Italian Journal of Psychology, 4, 65-76.

Crowder, R. G. (1976). Principles of learning and memory. Hillsdale, NJ: Erlbaum.

Ellis, A. W., Young, A. W., \& Flude, B. (1990). Repetition priming and face processing: Priming occurs within the system that responds to the identity of a face. Quarterly Journal of Experimental Psychology, 42A, 495-512.

Ellis, A. W., Young, A. W., Flude, B., \& Hay, D. C. (1987). Repetition priming of face recognition. Quarterly Journal of Experimental Psychology, 39A, 193-210.

Goshen-Gottstein, Y., \& Ganel, T. (2000). Repetition priming for familiar and unfamiliar faces in a sex-judgment task: Evidence for a common route for the processing of sex and identity. Journal of Experimental Psychology: Learning, Memory, \& Cognition, 26, 1198 1214.

GREENE, R. L. (1989). Spacing effects in memory: Evidence for a twoprocess account. Journal of Experimental Psychology: Learning, Memory, \& Cognition, 15, 371-377.

HaY, D. C. (2000). Testing instance models of face repetition priming. Memory \& Cognition, 28, 192-203.

Hintzman, D. L. (1974). Theoretical implications of the spacing effect. In R. L. Solso (Ed.), Theories in cognitive psychology: The Loyola Symposium (pp. 77-99). Potomac, MD: Erlbaum.

Hintzman, D. L., Block, R. A., \& Summers, J. J. (1973). Modality tags and memory for repetitions: Locus of the spacing effect. Journal of Verbal Learning \& Verbal Behavior, 12, 229-238.

Kirsner, K., Smith, M. C., Lockhart, R. S., \& King, M. L. (1984). The bilingual lexicon: Language-specific units in an integrated network. Journal of Verbal Learning \& Verbal Behavior, 23, 519-539.

McKone, E. (1995). Short-term implicit memory for words and nonwords. Journal of Experimental Psychology: Learning, Memory, \& Cognition, 21, 1108-1126.

McKone, E., \& Dennis, C. (2000). Short term implicit memory: Visual, auditory, and cross-modality priming. Psychonomic Bulletin \& Review, 7, 341-346

Morton, J. (1979). Facilitation in word recognition: Experiments causing change in the logogen model. In P. A. Kolers, M. E. Wrolstad, \& H. Bouma (Eds.), Processing models of visible language (pp. 259268). New York: Plenum.

Parkin, A. J., Gardiner, J. M., \& Rosser, R. (1995). Functional aspects of recollective experience in face recognition. Consciousness \& Cognition, 4, 387-398.

Roediger, H. L., III, Weldon, M. S., \& Challis, B. H. (1989). Ex- 
plaining dissociations between implicit and explicit measures of retention: A processing account. In H. L. Roediger III \& F. I. M. Craik (Eds.), Varieties of memory and consciousness: Essays in honour of Endel Tulving (pp. 3-41). Hillsdale, NJ: Erlbaum.

Rose, R. J. (1980). Encoding variability, levels of processing, and the effects of spacing of repetitions upon judgments of frequency. Memory \& Cognition, 8, 84-93.

Russo, R., \& Mammarella, N. (2002). Spacing effects in recognition memory: When meaning matters. European Journal of Cognitive Psychology, 14, 49-59.

Russo, R., Mammarella, N., \& Avons, S. E. (2002). Toward a unified account of spacing effects in explicit cued-memory tasks. Journal of Experimental Psychology: Learning, Memory, \& Cognition. 28, 819829.

Russo, R., Parkin, A. J., Taylor, S. R., \& Wilks, J. (1998). Revising current two-process accounts of spacing effects in memory. Journal of Experimental Psychology: Learning, Memory, \& Cognition, 24, 161-172.

Schacter, D. L. (1994). Priming and multiple systems: Perceptual mechanism of implicit memory. In D. L. Schacter \& E. Tulving (Eds.), Memory systems 1994 (pp. 233-268). Cambridge, MA: MIT Press.

Smith, M. C., Theodor, L., \& Franklin, P. E. (1983). The relationship between contextual facilitation and depth of processing. Journal of Experimental Psychology: Learning, Memory, \& Cognition, 9, 697712.

Snodgrass, J. C., \& Corwin, J. (1988). Pragmatics of measuring recognition memory: Application to dementia and amnesia. Journal of Experimental Psychology: General, 117, 34-50.

TenPenny, P. L. (1995). Abstractionist versus episodic theories of repetition priming and word identification. Psychonomic Bulletin \& Review, 2, 339-363.

\section{NOTES}

1. The $d^{\prime}$ values may not perfectly match the corresponding $d^{\prime}$ values in Table 3. This is because to calculate $d^{\prime}$ scores we employed the correction factor suggested by Snodgrass and Corwin (1988). Because the two conditions compared were obtained from the same participants, and because the correction factor was applied to each set of scores, the averaging of these values reflects this set of corrections. In Table 3 the correction was applied only once.

2 . We are grateful to an anonymous reviewer for this suggestion.

(Manuscript received July 11, 2001;

revision accepted for publication July 26, 2002.) 